Document downloaded from:

http://hdl.handle.net/10251/69999

This paper must be cited as:

Vargas, A.; Cuenca, L.; Boza, A.; Sacala, I.; Moisescu, M. (2016). Towards the development of the framework for inter sensing enterprise architecture. Journal of Intelligent Manufacturing. 27(1):55-72. doi:10.1007/s10845-014-0901-z.

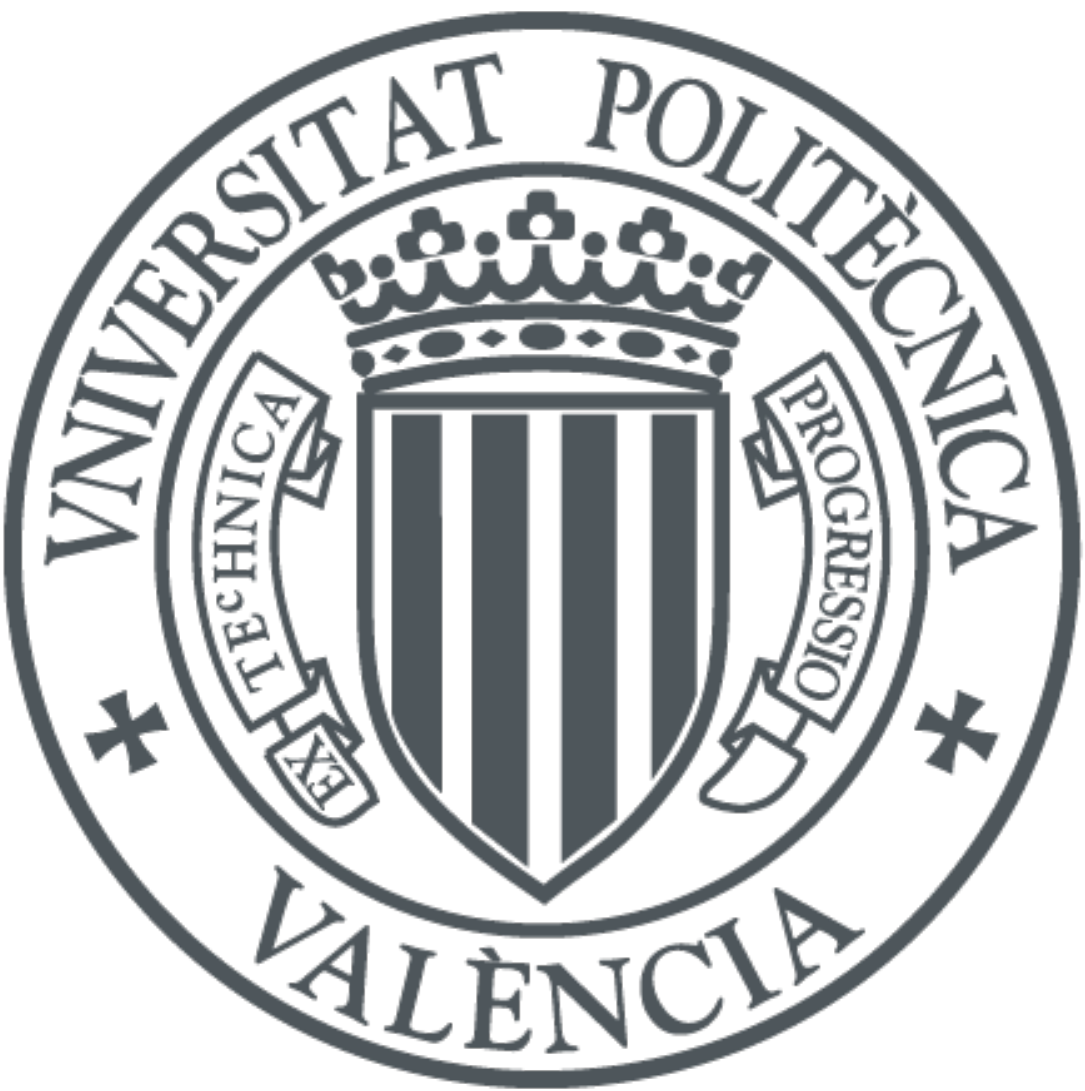

The final publication is available at

http://link.springer.com/article/10.1007\%2Fs10845-014-0901-z

Copyright Springer

Additional Information 


\title{
TOWARDS THE DEVELOPMENT OF THE FRAMEWORK FOR INTER SENSING ENTERPRISE ARCHITECTURE
}

\author{
Alix Vargas ${ }^{1}$, Llanos Cuenca $^{1}$, Andres Boza ${ }^{1}$, Ioan Sacala ${ }^{2}$, Mihnea Moisescu ${ }^{2}$ \\ ${ }^{1}$ Centro de Investigación en Gestión e Ingeniería de Producción (CIGIP). Universitat Politècnica de València. Camino de \\ Vera s/n Ed $8 \mathrm{G}-1^{\circ}$ y $4^{\circ}$ planta Acc D (Ciudad Politécnica de la Innovación) Valencia Spain. \\ alvarlo@posgrado.upv.es, 1lcuenca@cigip.upv.es, aboza@cigip.upv.es \\ ${ }^{2}$ University Politehnica Bucharest, Faculty of Automatics and Computer Science, 313, Splaiul Independetei, 60042 \\ Bucharest Romania \\ sacalaioan@yahoo.com,mamihnea@gmail.com
}

\begin{abstract}
Inter-Enterprise Architecture (IEA) is a new concept that seeks to apply the tools and methodologies of Enterprise Architecture (EA) in a collaborative context, in order to model collaborative organizations in an integral way. According to the main enterprise architectures proposed so far, an EA should be conformed at least for a framework, a methodology and a modelling language. Sensing Enterprise (SE) is a quality of an enterprise or a network that allow it reacting to business stimuli based on the Internet. The advent of these both fields is recent and there is not evidence of the use of IEA to modelling SE, finding an interesting gap to work on. In this sense, this paper proposes an initial Framework for Inter Sensing Enterprise Architecture (FISEA), which seeks classify, organize, store and communicate in a conceptual level the elements for inter sensing enterprise architecture and their relationships, ensuring their consistency and integrity. This FISEA provides a clear picture about the elements and views that make up collaborative network (CN) and their inter-relationships, based on the support of the Internet for its operation.
\end{abstract}

Keywords: Inter-Enterprise Architecture, Collaborative Networks, Digital Business Ecosystems, Future Internet.

\section{Introduction}

The current global market is dominated by globalization, which creates a strong competition atmosphere. This environment of globalization and competition directs the flow of business through the supply chain (SC) or, more recently, collaborative networks $(\mathrm{CN})$, since companies are not individually self-sufficient. Therefore, it is necessary that companies that make up these $\mathrm{CNs}$ are integrated and that they coordinate their processes to become more competitive and efficient, thus enabling the fulfilment of the overall objectives of the CN and its own objectives. On the other hand, 
organizations are more complex now, and require flexible business processes that are supported by an efficient information technology (IT) infrastructure. It is undisputed that IT and information systems (IS) have become strategic functions within organizations, and these functions have an increasing impact on business strategy, because IS/IT currently constitute for organizations a competitive advantage and a necessity to be sustainable over time.

In this sense, companies should be able to achieve two separate objectives. Companies must manage the increasing technological complexities accrued while they generate added value to business processes through the strategic alignment between business and IS/IT (Henderson and Venkatraman 1993), and at the same time companies must achieve integration and coordinate their processes with their partners in $\mathrm{CN}$ in the pursuit of efficiency and competitiveness to ensure survival in the global market. Achieving these goals is difficult because of the complexity of organizations, but using Enterprise Engineering (EE) with an Enterprise Architecture (EA) approach makes this easier (Vargas et al. 2013a).

The EA provides concepts, models and tools that enable organizations to face the challenges of integrating the strategic areas and business processes with the areas of IT, making them generate greater value to businesses, improve their performance, their communication and degree of integration, which ultimately will result in the creation of competitive advantage through effective IT support for the fulfilment of the strategies and objectives. Although the use of EA has been implemented and studied in depth in the individual enterprise, these concepts can be extended to CN.

Collaborative networks can allow small and medium enterprises (SMEs) to share information through the use of ICT in support of their business processes. If a $\mathrm{CN}$ is accurately created and managed, this allows SMEs to make being part of the $\mathrm{CN}$ more competitive, creating added value in their own business, enabling innovation and boosting learning and knowledge. In the context of CNs, two important approaches will be taken into account in the development of the proposal framework: Virtual Breeding Environments (Camarinha-Matos and Afsarmanesh 2008) and Digital Business Ecosystems (European Commission European Society and Media 2007).

The current knowledge era requires organizations to learn in a quicker and more flexible way while also taking advantage of the opportunities that technology offers. The Internet has become a necessity in business environments, but many SMEs cannot afford to use it as a management and operational tool in terms of cost, availability and trust. In order for the Internet to become useful as a real universal business system used by a $\mathrm{CN}$, it is necessary to spur joint efforts among society, government, research and industry. In this context, the European Commission, through the Future Internet Enterprise Systems Cluster (FInES Cluster 2012), is making an effort to involve industry and research institutions in different projects in order to create models and tools that enable the use of the Internet in everywhere. 
Following the ideas of the FInES Cluster, the Framework for Inter Sensing Enterprise Architecture (FISEA), proposed in this paper, is based in the use of the quality of sensing enterprise as technology that enables the interoperation between enterprises that form a CN.

Taking into account the big picture of the newly networked enterprise environment, and due the fact that so far there are not research that connect these fields finding a gap in the literature, a research question emerges: Is it possible to link the fields of enterprise collaboration, collaborative networks, enterprise architectures, strategic alignment and sensing enterprise in order to create new tools that allow modelling $\mathrm{CN}$ to boost interoperability among enterprises? For the purposes to answer this question, the current document accomplishes a deep review of these fields and their relationship with one another, providing the hypothesis of the research question that also helps to fill the gap founded, since those fields can be used together in a new and big concept of Inter-Enterprise Architecture (IEA). In addition to this, the document goes beyond the state of the art proposing a first framework for sensing enterprise architecture and its metamodel as a novel tool for modelling $\mathrm{CN}$ in sensing environments.

The paper is structured as follows: Section 2 describes the related work in the fields of: strategic alignment, enterprise collaboration, collaborative networks, enterprise engineering /enterprise architecture and future Internet. It is explained the new concept of IEA and its motivation in linking these fields to propose new tools for boosting $\mathrm{CN}$ in sensing environments. Section 3 presents our proposal of FISEA. Section 4 presents the FISEA meta-model that helps to endorse the correct definition of the elements in the FISEA and its validation. Section 5 reports the results and provokes a critical discussion. Finally, Section 6 presents the main conclusions and future steps in this research.

\section{Related work}

\subsection{Strategic Alignment}

It is clear that CNs have to be able to manage the technological complexities of their IS, while ensuring generation of added value to business processes. This can only be achieved if there exists alignment between business and IS / IT, a concept that became stronger in the 1990s thanks to the Strategic Alignment Model (SAM) proposed by (Henderson and Venkatraman 1993). Although the theory suggests that there should be a strategic fit between the internal and external domains of both business and IT, and that there should also be a functional integration between business and IT, in reality, the implementation of the alignment is quite complicated to carry out, due to the fact that the studies, models and/or frameworks developed for this purpose are scarce, and their utility is often not validated in the real world. 
According to the most important elements provided for several authors, in Vargas et al. (2013b), we suggested the following definition for strategic alignment: "The strategic alignment of business and IS/IT is a dynamic and continuous process that enables integration, adjustment, consistency, understanding, synchronization and support between business strategies and strategies of IS / IT, in order to contribute and maintain the correct performance of the organization, creating a competitive advantage that is sustained over time".

The foundation bases of SAM are theoretical and not practical. However, (Luftman 2004) introduces, with his alignment maturity model (AMM), a practical component that SAM did not have. This model is based on the concepts that are conceptualized in the SAM, but also incorporates a practical aspect to the field of strategic alignment, proposing a model to measure the degree of maturity of the alignment that has the business and IS/IT. This enables the company that applies it to identify it, how it is, where and how to improve.

Several authors have extended or used SAM for different conceptual aspects, seeking to ensure strategic alignment (Maes 1999; Hu and Huang 2006; Dong et al. 2008; Wang et al. 2008; Mekawy et al. 2009). Other authors have conducted their research and their findings were based on the AMM to propose practical conceptual models (Adaba et al. 2010; Estimali et al. 2010). However, all previous models are only applicable to their individual line of business. The market competition atmosphere is rapidly progressing towards a more collaborative environment. Therefore, some authors have proposed a few models for alignment in the inter-enterprise context (Santana et al. 2008; Pijpers et al. 2009).

\subsection{Enterprise Collaboration}

Enterprises today do not compete individually, and now CNs compete with each other in search of increased profits and generating more customer value. Therefore, the necessity of a high degree of integration between partners that make up these $\mathrm{CN}$ is imminent (Plaza et al.2010), and this degree of integration may be achieved through collaborative mechanisms to ensure the alignment of individual plans in the search for achieving a goal of a joint plan. Thus, enterprise collaboration emerges as a tool that allows members of $\mathrm{CN}$ to be making decisions together, based on shared information and the exchange of a bilateral way, which allows them to coordinate and synchronize activities with the objective of satisfying the market and increasing joint profits (Vargas et al. 2013b). Also, various forms of collaboration can improve chances to capture valuable business opportunities, address market demands and share resources and competences in very competitive and rapidly changing environments (Swarnkar et al. 2012). 
In Vargas et al. (2011), enterprise collaboration is defined as: “A joint process between members of the SC, where the decisions are made jointly, based on the information shared and exchanged on a bilateral form, achieving coordinate and synchronize joint activities to meet customer requirements and achieve process efficiency sets to generate a mutually beneficial".

According to Kilgeret al. (2008), the collaboration process consists of six activities. However, this generic process has not taken a certain crucial aspect into account: the definition of how to share benefits equitably to ensure the stability of the collaboration (Audy et al. 2010). The solution to this problem is provided by Stadtler (2009), which proposes the definition of a system of compensatory payments, which may agree with the definition phase of the negotiation and exception handling and can be implemented when evaluating the results. Another previously unconsidered aspect in this generic process is the need for feedback between the parties once they have completed the process of collaboration in the stipulated horizon, who also must review the plan and modify it if necessary. Fig. 1 shows this process graphically, where the orange colored arrows represent the changes proposed (Vargas et al.2013b).

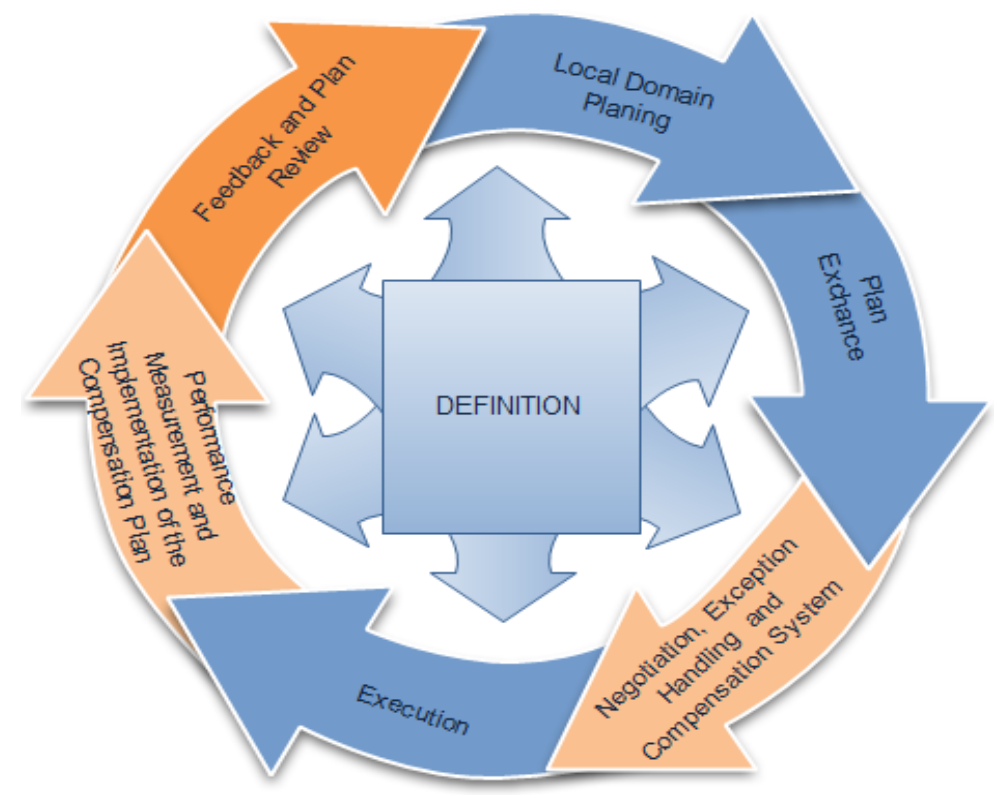

(Adapted from Kilger et al. 2008)

Fig. 1. Enterprise collaboration process

\subsection{Collaborative networks}

In the new market environment, enterprises have to deal with the complexity of contemporary products (Mehandjiev and Grefen 2010), new customer requirements, geographically distributed partners, and a constantly changing technological environment. This is a big challenge that must be approached with thorough consideration, especially by SMEs due to a 
shortage of resources (both monetary and skilled workforce) and simply-used and affordable ICT solutions facing this challenge by themselves. Therefore, SMEs have to create CNs in order to be competitive and survive such a turbulent environment.

The concept of $\mathrm{CN}$ has its origin in the traditional SC, that is defined by the Council of Supply Chain Management Professionals (2010), as: "The material and informational interchanges in the logistical process stretching from acquisition of raw materials to delivery of finished products to the end user. All vendors, service providers and customers are links in the supply chain". Nevertheless, this concept has evolved over time because of the dynamic environment in which different organizations are attempting to become fluent in the new approach of CN. According to CamarinhaMatos and Afsarmanesh (2005), "Collaborative Network is a network consisting of a variety of entities (e.g. organizations, people, machines) that are largely autonomous, geographically distributed, and heterogeneous in terms of their operating environment, culture, social capital and goals, but that collaborate to better achieve common or compatible goals, thus jointly generating value, and whose interactions are supported by computer networks".

CNs are manifested in a large variety of forms, which have been suggested by (Camarinha-Matos et al. 2008): Virtual Enterprises, Virtual Organization, Extend Enterprise, Virtual Community and Virtual Teams. The term "virtual" or "digital" in the new forms of organizations stems from the fact that these CNs act as a single entity, thanks to their well organized communication systems and coordination mechanisms that are enabled and boosted by computer and Internet. All of those virtual entities can benefit from the experiences of previous projects with similar team members or objectives (Palmer et al. 2013), through the continuous learning that generates and create knowledge.

When CNs (industry), Researcher Institutions, Universities and Governmental Organizations join efforts in order to create a community that looks for increasing industrial competitiveness, they are creating traditional "Clusters". A cluster represents an association or pool of enterprises and related supporting institutions that have both the potential and the motivation to cooperate with each other through the establishment of a long-term cooperation agreement (CamarinhaMatos et al. 2008). These clusters are established within given geographic regions, taking advantage of common business cultures and senses of community and cooperation. They are also typically focused on one or a few specialty sectors of a specific region (European Commission European Society and Media 2007). However, these clusters have to evolve due to the dynamic environment in which they are operating and taking advantage of the support of the new virtual or digital technologies. The European Commission (2007) proposes the concept of "extended dynamic clusters", which are virtual clusters that transcend location, focus on interregional or international markets, are IT enabled, and operate as ad-hoc business networks that can aggregate and reconfigure capabilities from different firms. Thus, the conceptual foundation of 
Clusters has given origin to two new fields: Virtual Breeding Environments (Camarinha-Matos and Afsarmanesh 2008) and Digital Business Ecosystems (European Commission European Society and Media 2007).

The Virtual organizations Breeding Environment (VBE) represents a long-term "strategic" alliance, cluster, association, or pool of organizations that provides the necessary pre-conditions for cooperation among their member organizations and facilitates the fluid establishment of Virtual Organizations (VOs) in response to the emerging collaboration opportunities in the market / society (Camarinha-Matos and Afsarmanesh 2005, Camarinha-Matos et al. 2008, Romero et al. 2010).

A Digital Business Ecosystem (DBE) is a new form of dynamic business interaction and global co-operation among organizations and business communities, enabled by digital ecosystem technologies that foster local economic growth. The main characteristics of a DBE are: knocking down the barriers to distributed cooperative work and shared knowledge production, allowing the synchronization of dynamic social and communication networks over ever-shortening time scales, as well as pushing the ecosystem metaphor towards a distributed cognitive system and a collective intelligence (European Commission European Society and Media 2007).

According to the previous paragraphs, these two approaches are rather similar, and in this paper we will use the term DBE, because it is considered that ecosystems provide a common breeding environment within which several CNs may be created and managed, by sharing a set of common principles, ontologies and practices usually ruled by the ecosystem manager (Franco et al. 2012).

In the context of DBE, the role of assuming the organisms involved, is crucial, as well as the responsibilities related to each role. The main actors and their roles and responsibilities associates to DBE have been proposed by (European Commission European Society and Media 2007) and (Afsarmanesh et al. 2008).

Fig. 2 shows the graphical representation the relationships between entities in a business ecosystem, where traditional SCs make up CN, which makes up a Digital Cluster (DC) in which the Regional Catalyst (RC) connects all actors including Universities (U), Governmental Organisms (GO), brokers (B) and other institutions (OI). Inside of each CN, different enterprises play the role of Virtual Organization Coordinator (VOC) and Virtual Organization Planner (VOP). The works by (European Commission European Society and Media 2007; Ermilova and Afsarmanesh 2007; Afsarmanesh et al. 2008) have a deep analysis of the roles, profiles and competences of these entities. The relationships between actors in this business environment can be for business or learning and the $\mathrm{RC}$ is in charge of managing this 
knowledge environment. On one hand, the business relationship can already exist between members of the $\mathrm{CN}$, and they are referred to as buying or selling goods or services. On the other hand, the learning relationships in a business ecosystem are channelled for the $\mathrm{RC}$, where each organization that joins into a $\mathrm{CN}$ tends to transfer its knowledge to the $\mathrm{CN}$, which is an individual knowledge. When the $\mathrm{CN}$ starts working, the learning process begins, and the ability to learn by identifying, assimilating, transforming and exploiting existing resources is gained to generate new knowledge. This way, the $\mathrm{RC}$ absorbs the generated knowledge in the collaboration processes and shares it with other $\mathrm{CN}$, generating and disseminating knowledge.

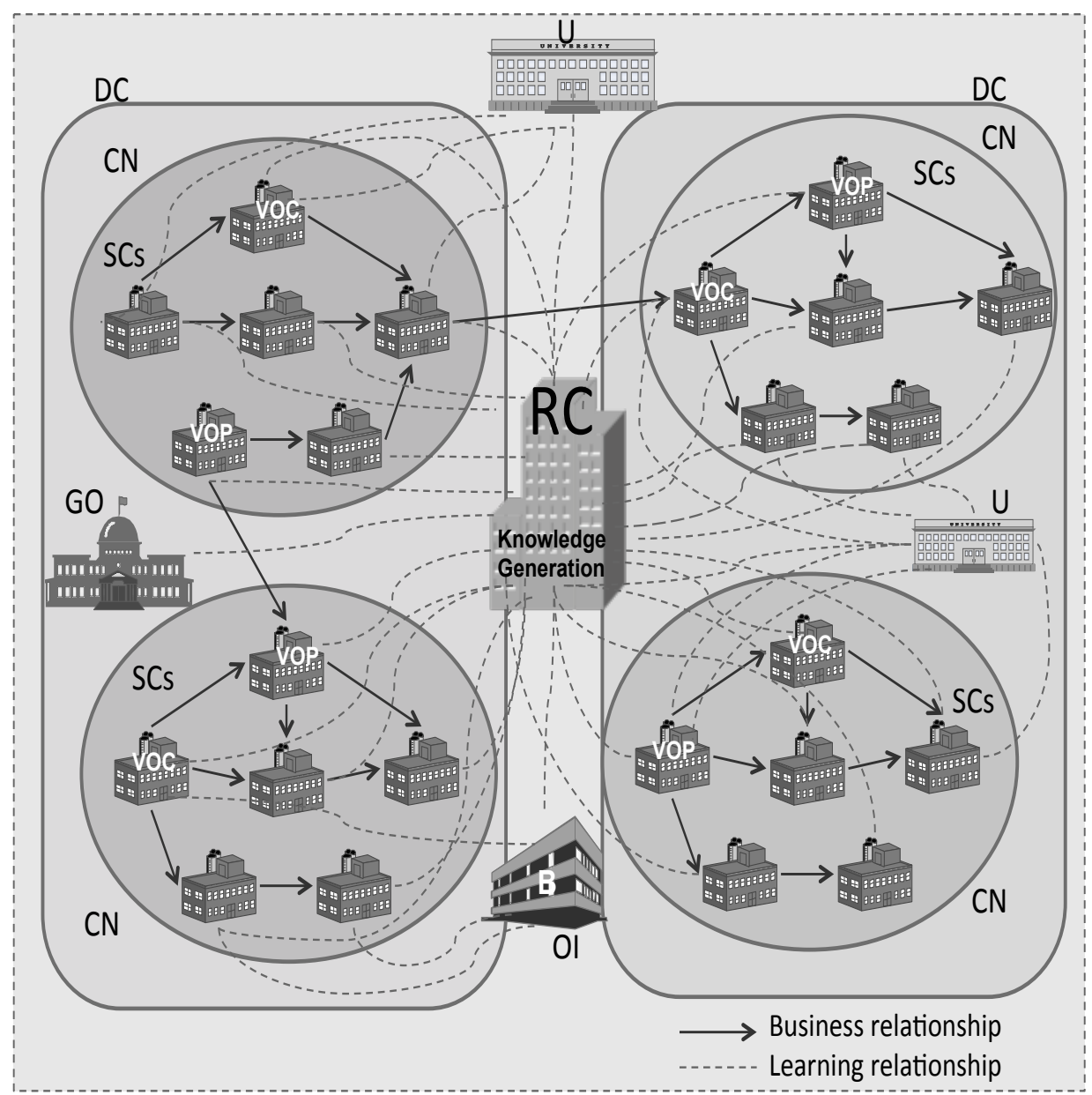

Fig. 2. Relationship between different entities in a business ecosystem.

\subsection{Enterprise Engineering and Enterprise Architecture}

Enterprise engineering is the discipline applied to carrying out any efforts to establish, modify, or reorganize any enterprise (ISO 15704 2000). This discipline is responsible for defining, structuring, designing and implementing enterprise operations as communication networks of business processes, which comprise all their related business knowledge, operational information, resources and organization relationships (Kosanke et al. 1999). The field of enterprise engineering is concerned with understanding, defining, designing and redesigning business entities, which includes all knowledge and organizational relationships, as well as life cycles (Cuenca 2009). Therefore, enterprise 
engineering facilitates the integration of all elements of the enterprise. Enterprise Integration deals with facilitating information flows, systems interoperability and knowledge sharing among any kind of organization (Vernadat 2003).

Achieving enterprise integration through the enterprise engineering is possible thanks to the use of enterprise architectures. In (Vargas et al. 2011), Enterprise Architecture is defined using the main elements that are provided by several authors (Schekkerman 2004; Lankhorst 2009; Arango et al. 2010; Stelzer 2010), as: “A discipline that provides a set of principles, methods, models and tools used for analysis, design and redesign of a company, thus allowing to represent and document the elements that form the company (such as organizational structure, business processes, systems information and technology infrastructure) and the relations, organization and joints between these elements, allowing the company to be represented in a holistic and integrated perspective, in order to achieve the business objectives and facilitate decision-making processes"

The main elements of enterprise architecture and their relationships are shown in Fig 3. Three basic elements have been identified (highlighted in orange colour): methodology, framework and modelling language (Vargas et al. 2011). These elements must be provided by enterprise architectures for successful implementation within the enterprise. The methodology defines how the EA will be implemented and how it will develop, use and archive the documentation. The framework allows for structuring of the elements of the enterprise architecture and their relationships in a graphical and simple way, taking into account different views or perspectives and the life cycle phases. Finally, the identification of a modelling language allows modelling and understanding the relationship between the views that make the company, in a structured way.

The identification of the core components of enterprise architectures allows for the proposal of a classification of the different architectures that have been designed in recent years in:

- Total enterprise architecture (TEA): Those architectures that define all the three elements.

- Partial enterprise architecture (PEA): Those architectures that define just one or two out of the three elements. This category also includes those architectures that have been designed for specific governmental exclusively for their use.

According to the above classification, the following enterprise architectures are considered a type of TEA: CIMOSA (CIMOSA Association 1996), GIM-GRAI (Chen et al. 1997), GERAM (Force, IFIP-IFAC Task 1998), IE-GIP (Ortiz 1998) and its extension that took the same name (Cuenca 2009), TOGAF-ADM (THE OPEN GROUP 2011), and ARDIN (Chalmeta and Grangel 2003). On the other hand, the following architectures are considered types of PEA: 
Zachman Framework (Zachman 1997), DoDaf (United States Department of Defense 2010), FEAF (Executive Branch of the U.S. Federal Government 2012), TEAF (U.S. Department of the Treasury 2000), VECCF (Choi et al. 2008) and E2AF (Schekkerman 2004).

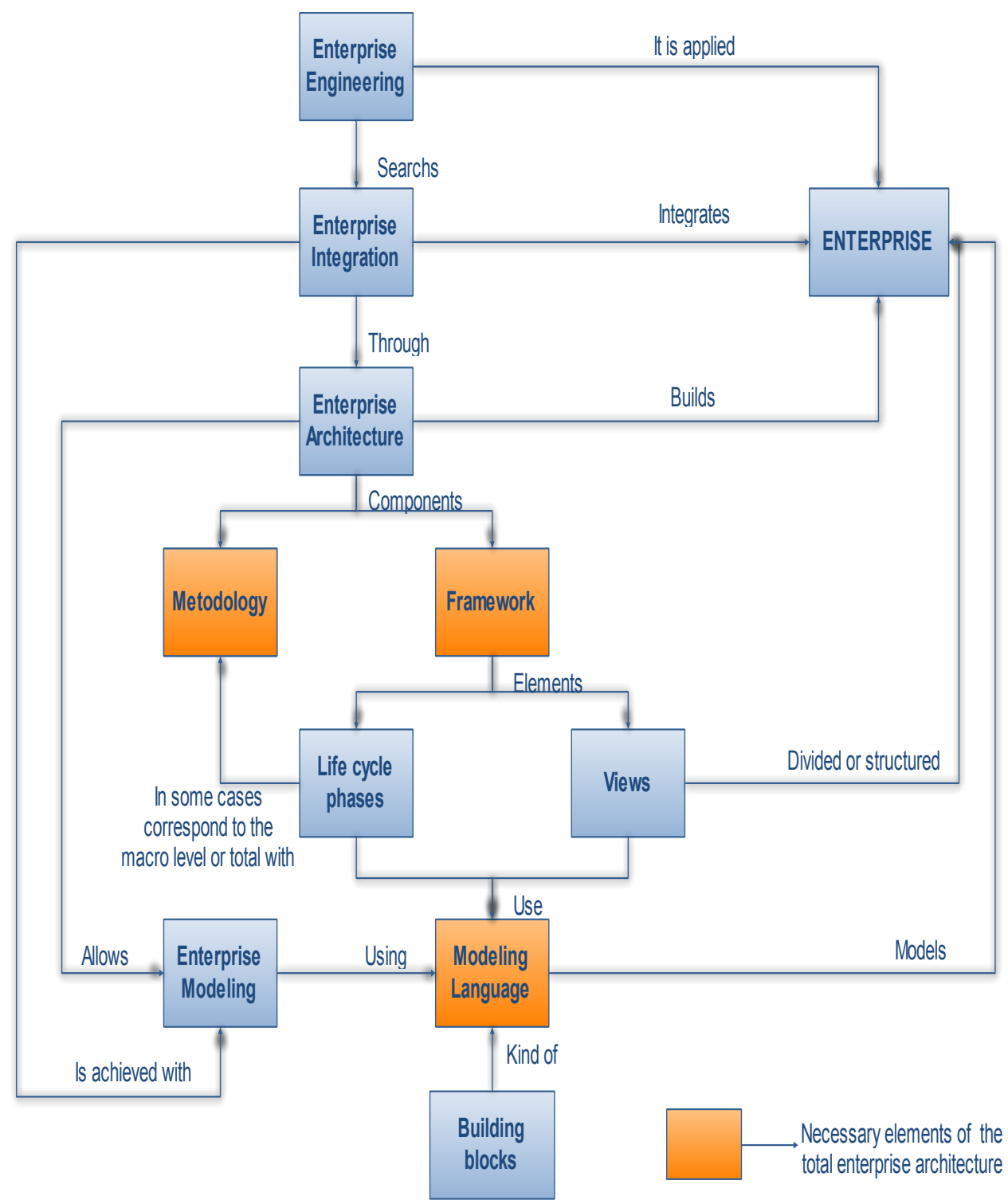

(Adapted from Cuenca et al. 2011)

Fig. 3. Elements in Enterprise Architectures

\subsection{Future Internet}

In the new economic environment, ICTs and the Internet are ubiquitous (Afsarmanesh and Msanjila 2008). This advent has led to the development of varios forms of virtual collaboration, thought networks (Coutinho, et al. 2014). The rapid growth of the Internet has enhanced computing, sharing and communication capabilities, but has also introduced uncertainties regarding the future of existing traditional business models. In order to sustain and increase business competitively, enterprises should embrace these new technologies carefully taking into account different vital aspects: 
security, agility, accuracy, interoperability, affordability and reliability. On the other hand, there are some important requirements for the implementation of IT solutions into SMEs in a context of collaboration. According to Mehandjiev and Grefen (2010), these are: cost, time, flexibility, privacy, and trust.

According to FInES Cluster (2012), the next decade is expected to see a thorough change in the way enterprises operate, mainly due to the advent of Future Internet and the maturity achieved by enterprises in adopting new socio-technical solutions based on the former. The FInES Cluster, in its Roadmap, proposes 9 paradigmatic enterprise profiles concerning to the Qualities of Being (QB) of the Future Internet-based Enterprises (FInES):

- QB1. Humanistic Enterprise (HE): HE accepts to put the persons at the centre

- QB2. Inventive Enterprise (IE): IE is capable of dealing with the entire lifecycle of innovation

- QB3. Agile Enterprise (AE): AE is capable of reacting to endogenous and exogenous contingencies with flexibility and adaptability.

- QB4. Cognisant Enterprise (CE): CE reaches beyond knowledge management.

- QB5. Sensing Enterprise (SE): In SE, the enterprise is seen as a smart complex entity capable of sensing and reacting to (business) stimuli.

- QB6. Community-oriented Enterprise (CoE): $\mathrm{CoE}$ uses the collective intelligence of different communities, both internal (among employees) and external (among customers and suppliers), to improve enterprise operations and performance.

- QB7. Liquid Enterprise (LE): LE is the enterprise which boundaries are blurry, because of different forms of collaboration with different stakeholders.

- QB8. Glocal Enterprise (GE): A GE is the enterprise that focuses its strategic in the present time in a local marked in a synchronic view, but also have into account, at the same time, its future in a global marked in a diachronic view.

- QB9. Sustainable Enterprise (SuE): $\mathrm{SuE}$ is an enterprise that has into account three facets of sustainability: economic, social, and environmental.

In the current research, we are going to use the qualities of an SE, because in a collaborative environment, the network thought sensors generate data and information that trigger business collaborative processes, and this kind of new networking sensor business has to model in a structured and integral way, allowing for integration and interoperability among enterprises and their applications (Moisescu et al. 2012).

\subsection{Emergent concept of Inter-Enterprise Architecture (IEA)}


After a thorough analysis of the current literature in the fields summarized above, we have identified trends, studied models that have been presented and their relationships with one another, structured main concepts and associated issues, analysed main ideas and common points, and identified a large gap in the literature, due to the fact that there is not currently any documentation tying these fields of research together.

The goal of an IEA is to search for applications of the tools and methodologies of enterprise architecture, which have been developed for the individual enterprise, but adapting them in a collaborative environment between several enterprises that make up CNs (Vargas, el al. 2013a). This will facilitate the collaboration process of integration between enterprises with their information systems and technology systems (based on Internet), supporting joint processes, reducing risks and redundancies, increasing customer service and responsiveness, reducing technology costs and allowing for alignment on multiple levels: joint business processes and ICT. In Fig. 4, the field of intended study is represented in the spotlight.

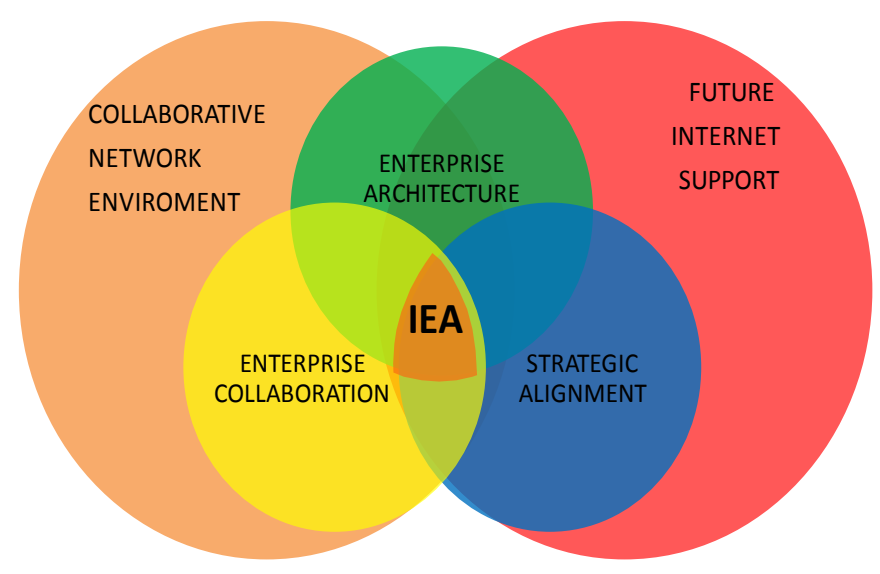

Fig. 4. Origin of IEA concept.

The implementation of an IEA is part of establishing a set of architectural guidelines that ensure comprehensive development between models and inter-enterprise needs, with joint business processes and ICT. This set of ICT strategic guidelines must be based on joint strategic planning and corporate recognition of business strategies and activities that support such planning. These guidelines will also be responsible for spawning the necessary information for the joint operation of organizations and technologies required to support joint operations and new technology implementation processes in response to ever-changing needs and jointly involved organizations. 
In this IEA, technology plays a definitive role, according to the concepts of DBE that consider that technology must be the medium that facilitates the formalization and distribution of the knowledge from which the same technology emerged. In other words, technology becomes a catalyst for development of enterprises, SCs, CNs and DCs. Therefore; technology accelerates the growth and harmony of the DBE.

\section{Proposal}

The motivation for this research is to contribute with new tools for CNs in their collaborative and modelling process that allows them boosting interoperability in sensing environments. Those new tools are based on EA and more specifically in the new concept of IEA. Following the outcomes of Section 2.3, the three principal elements in any EA are: Framework, Methodology and Modelling Language (Fig. 3). In this paper, we propose a framework for modelling CNs in the context of sensing enterprise called Framework of Inter Sensing Enterprise Architecture (FISEA).

In the context of an EA, several authors have proposed definitions for the term of Framework (Zachman 1997; ISO 15704 2000; Cuenca et al. 2005; ISO/CEN 19439 2006; Schekkerman 2006), and in order to join the main components of these definitions together, we propose the following: "The framework is a logical structure for classifying, organizing, storing and communicating conceptual level elements or components of the architecture and their relationships, ensuring consistency and integrity. This structure defines the scope of enterprise architecture and provides a basis for assembly and development".

In order to identify the principal differences and similarities between different frameworks, which have been proposed until now, the following surveys have been absorbed into our analysis:

- The architectures defined in section 2.4 as Total Enterprise Architecture: CIMOSA, GIM-GRAI, GERAM, IE-GIP (Including its extension), TOGAF-ADM and ARDIN.

- In the context of CNs or virtual enterprise integration: ARCON- A Reference Model for Collaborative Networks (Camarinha-Matos and Afsarmanesh 2008), VERA - Virtual Enterprise Reference Architecture (Vesterager et al. 2002) (Vesterager, Tølle and Bernus, VERA: Virtual Enterprise Reference 2002), ARDIN-EVEI - ARDIN Extension for Virtual Enterprise Integration (Chalmeta and Grangel 2003).

Most of these architectures use similar perspectives in their frameworks: life cycle perspective and modelling views perspective. 
Life cycle perspective: this perspective represents the set of generic phases, which the entity (enterprise, SC or CN) may go through over its entire life history, from its creation until its decommissioning. Table 1 shows a comparative analysis of the life cycle phases that each architecture proposes, compared with the life cycle phases that the standard ISO/CEN 19439 (2006) proposes.

It is observed that TOGAF-ADM does not manage the concept of life cycle in its framework; the number of life cycle phases for architectures is between three and eight. GERAM phases correspond identically with the phases of the standard, because this is based on GERAM for its design. VERA also appears to be based on GERAM. New phases of the life cycle are proposed for IE-GIP and ARCON, which are not included into the standard.

Table 1. Comparative analysis of the life cycle phases of different frameworks.

\begin{tabular}{|c|c|c|c|c|c|c|c|c|c|c|}
\hline \multirow{2}{*}{\multicolumn{2}{|c|}{ LIFE CYCLE PHASES }} & \multicolumn{6}{|c|}{ TOTAL ENTERPRISE ARCHITECTURES (TEA) } & \multicolumn{3}{|c|}{$\begin{array}{l}\text { COLLABORATIVE } \\
\text { NETWORK ARCHITECTURES } \\
\text { (CNA) }\end{array}$} \\
\hline & & CIMOSA & $\begin{array}{l}\text { GIM- } \\
\text { GRAI }\end{array}$ & GERAM & IE-GIP & $\begin{array}{l}\text { TOGAF- } \\
\text { ADM }\end{array}$ & ARDIN & ARCON & $\begin{array}{l}\text { ARDIN- } \\
\text { EVEI }\end{array}$ & VERA \\
\hline \multirow{7}{*}{$\begin{array}{l}\text { Life cycle } \\
\text { phases } \\
\text { defined in } \\
\text { ISO 19439 } \\
(2006)\end{array}$} & $\begin{array}{l}\text { Domain } \\
\text { identification }\end{array}$ & & & $=$ & $=$ & & & & $=$ & $=$ \\
\hline & $\begin{array}{l}\text { Concept } \\
\text { definition }\end{array}$ & & $=$ & $=$ & $=$ & & $=$ & & \pm & $=$ \\
\hline & $\begin{array}{l}\text { Requirements } \\
\text { definition }\end{array}$ & $=$ & & $=$ & & & $=$ & & $=$ & $=$ \\
\hline & $\begin{array}{l}\text { Design } \\
\text { specification }\end{array}$ & $=$ & $=$ & $=$ & & & $=$ & & $=$ & $=$ \\
\hline & $\begin{array}{l}\text { Implementation } \\
\text { description }\end{array}$ & $=$ & & $=$ & \pm & & \pm & & $=$ & $=$ \\
\hline & $\begin{array}{l}\text { Domain } \\
\text { operation }\end{array}$ & & $=$ & $=$ & & & \pm & $=$ & $=$ & $=$ \\
\hline & $\begin{array}{l}\text { Decommission } \\
\text { definition }\end{array}$ & & & $=$ & & & $=$ & \pm & $=$ & $=$ \\
\hline \multirow{4}{*}{$\begin{array}{l}\text { Other phases } \\
\text { provided by } \\
\text { the different } \\
\text { architectures }\end{array}$} & $\begin{array}{l}\text { Definition } \\
\text { business process }\end{array}$ & & & & & & & & & \\
\hline & Creation & & & & & & & & & \\
\hline & Evolution & & & & & & & & & \\
\hline & Metamorphosis & & & & & & & & & \\
\hline \multicolumn{11}{|l|}{ Conventions: } \\
\hline$=$ & \multirow{3}{*}{\multicolumn{10}{|c|}{$\begin{array}{l}\text { It is not included into the framework } \\
\text { It is included into the framework with the same o similar name } \\
\text { It is not included in an explicit form but it can be deduced from the context } \\
\text { Other phases provided by different architectures }\end{array}$}} \\
\hline \pm & & & & & & & & & & \\
\hline & & & & & & & & & & \\
\hline
\end{tabular}

Modelling views perspective: According to ISO 15704 (2000), a modelling view is a subset of data of the integrated model that allows the modeller and the user enterprise business model filter their observations of the real world, placing emphasis on those aspects that are relevant to their particular interests and context. Each enterprise architecture defines its 
own views, and this definition depends on the approach of the architecture so there can be no consensus among the number of views that must have an architecture. In order to standardize the number of views, ISO/CEN 19439 (2006) proposes the following basic views: function, information, resources and organization. Table 2 shows a comparative analysis of the modelling views that propose each architecture, compared with the views that the standard ISO/CEN 19439 (2006) proposes.

Table 2. Comparative analysis of modelling views of different frameworks.

\begin{tabular}{|c|c|c|c|c|c|c|c|c|c|c|}
\hline \multirow{2}{*}{\multicolumn{2}{|c|}{$\begin{array}{l}\text { FRAMEWORK MODELLING } \\
\text { VIEWS }\end{array}$}} & \multicolumn{6}{|c|}{ TOTAL ENTERPRISE ARCHITECTURES (TEA) } & \multicolumn{3}{|c|}{$\begin{array}{c}\text { COLLABORATIVE } \\
\text { NETWORK ARCHITECTURES } \\
\text { (CNA) }\end{array}$} \\
\hline & & CIMOSA & $\begin{array}{l}\text { GIM- } \\
\text { GRAI }\end{array}$ & GERAM & IE-GIP & $\begin{array}{l}\text { TOGAF- } \\
\text { ADM }\end{array}$ & ARDIN & ARCON & $\begin{array}{l}\text { ARDIN- } \\
\text { EVEI }\end{array}$ & VERA \\
\hline \multirow{4}{*}{$\begin{array}{l}\text { Modelling } \\
\text { views } \\
\text { defined in } \\
\text { ISO } 19439 \\
(2006)\end{array}$} & FUNCTION & $=$ & \pm & $=$ & \pm & \pm & $=$ & $=$ & $=$ & $=$ \\
\hline & INFORMATION & $=$ & $=$ & $=$ & $=$ & $=$ & $=$ & & $=$ & $=$ \\
\hline & RESOURCES & $=$ & & $=$ & $=$ & & $=$ & \pm & $=$ & $=$ \\
\hline & ORGANIZATION & $=$ & & $=$ & $=$ & & & \pm & & $=$ \\
\hline & DECISION & & & & & & & & & \\
\hline & DATA & & & & & & & & & \\
\hline & APPLICATIONS & & & & & & & & & \\
\hline & $\begin{array}{l}\text { INFORMATION } \\
\text { SYSTEMS } \\
\end{array}$ & & & & & & & & & \\
\hline & TECHNOLOGY & & & & & & & & & \\
\hline & BEHAVIOURAL & & & & & & & & & \\
\hline & MARKET & & & & & & & \multirow{4}{*}{$\begin{array}{l}\text { Exogenous } \\
\text { interactions }\end{array}$} & & \\
\hline & SUPPORT & & & & & & & & & \\
\hline & SOCIETAL & & & & & & & & & \\
\hline & CONSTITUENCY & & & & & & & & & \\
\hline \multicolumn{11}{|c|}{ Conventions: } \\
\hline & \multirow{4}{*}{\multicolumn{10}{|c|}{$\begin{array}{l}\text { It is not included into the framework } \\
\text { It is included into the framework with the same o similar name } \\
\text { It is not included in an explicit form but it can be deduced from the context } \\
\text { Other views provided by different architectures }\end{array}$}} \\
\hline$=$ & & & & & & & & & & \\
\hline \pm & & & & & & & & & & \\
\hline & & & & & & & & & & \\
\hline
\end{tabular}

All frameworks of enterprise architectures are analysed using the concept of views, but the number of views for each framework varies, ranging from three to eight. The two most common views in the architectures studied are "Function" and "Information". ARCON demonstrates a difference between two perspectives: Endogenous Elements and Exogenous Interactions. The first common link relates the representation of the $\mathrm{CN}$ from inside, and the second common link refers to the abstract representation of the $\mathrm{CN}$ as seen from the outside. In the context of a DBE, the exogenous interactions are quite complex, and this complexity is very difficult to model. However, these exogenous interactions must facilitate and trigger the self-organization, self-learning, self-adaptation and self-evolution of the DBE, and the RC has these tasks to form its role. This way, RC facilitates and hastens the DBE's evolution. Also, RC supports the consensus creation among 
DBE and develops an atmosphere of trust around it. RC must guarantee, guide, and coordinate different actors, and ensure the availability of a technical platform that facilitates the collaboration and different forms of support. These forms of support can include: technical, structural, legal, market, societal, etc. This shows why this perspective is not going to be included in the argument for the FISEA.

\subsection{Framework for Inter Sensing Enterprise Architecture (FISEA)}

In seeking to propose a useful reference framework for modelling a collaborative sensing enterprise, we propose the FISEA, of which the structure and elements are shown in the Fig. 5. Following the guidelines of previous work on enterprise architecture frameworks, we must take into account the following perspectives: modelling views, life cycle phases and modelling detail level.

Modelling views: The base architecture for defining views in FISEA has been IE-GIP (Ortiz 1998) and its subsequent extension (Cuenca 2009), which in turn was based on CIMOSA and GERAM. Figure 5 shows the origin of FISEA modelling views and their evolution. The proposed evolution is in terms of content and form: The function view of IEGIP is divided into business and processes views in order to facilitate the modelling, due to the fact that the business vision focuses on strategic issues, and vision process focuses on the tactical and operational aspects. The information view of IE-GIP evolves within the knowledge view because the information in a continuous learning process among CNs boosts knowledge. The resources and data views of IE-GIP have been joined because data is a resource that needs an enterprise in order to run processes. This way, the modelling results become more compact. The applications and technology views of IE-GIP have come together in a single view of Sensors behaviour, in order to reduce the complexity of modelling.

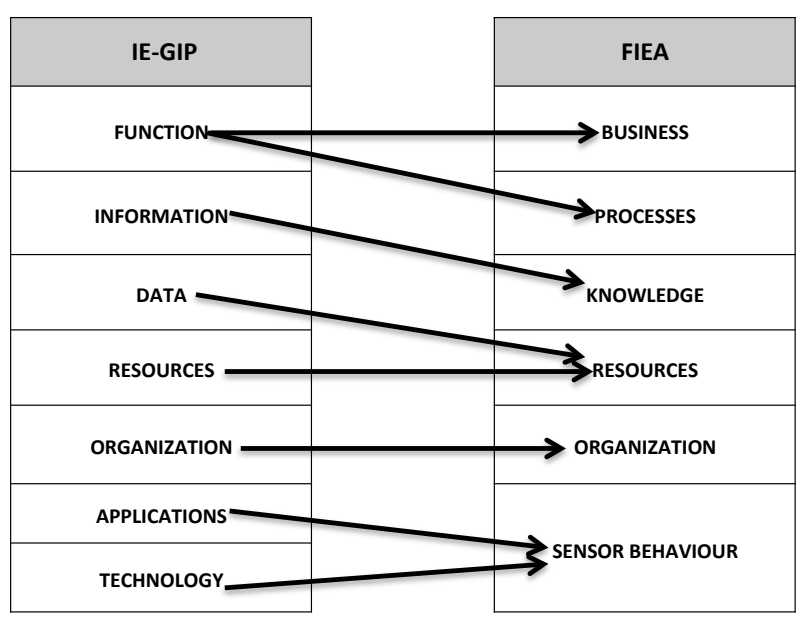

Fig. 5. Origin of FISEA modelling views 
- Business view: This view represents the strategic aspects that must be taken into account in the collaborative network, including negotiation, contract, objectives, key performance indicator (KPI), monitoring, and performance assessment. This view includes decision and behavioural point of views.

- Processes view: This view represents $\mathrm{CN}$ processes, functionality, performance, inputs and outputs. This view includes a definition of the AS-IS Process and the TO-BE Process, as well as process operation and process improvement.

- Knowledge view: In the continuous learning process where organizations are involved, the information that they handle becomes knowledge. Thus, it is a differentiator asset to the $\mathrm{CN}$.

- Recourses view: This view represents the capabilities and resources to complete business processes and the roles and responsibilities of individuals and organizational units within the $\mathrm{CN}$. This view includes physical resources, human resources and data.

- Organization view: This view allows the representation and modification of the organizational structure and the teams involved into the $\mathrm{CN}$ and decision-making of the $\mathrm{CN}$.

- Sensors behaviour view: One of the main characteristics is the context sensing capability enabled by cross-domain multiple networked sensors through Wireless Sensor Networks or by mobile sensors (mounted on robots, vehicles or linked to smartphones) that can provide a better coverage of the environment, as well as the ability to adapt to the sensing network by focusing on the current "hot-spots". As a direct consequence of multiple types of sensors and the large scale at which this kind of systems operate, another defining characteristic is the presence of heterogeneous information flows. Data collected from sensors must trigger a chain of events leading to changes within enterprise business process, collaboration mechanism or organizational framework. Such changes can be achieved in terms of simple sense-act enterprise behaviour (direct link between sense and act) or more complex sense-plan-act approach (decision level) (Sacala et al. 2013).

Life Cycle Phases: The life cycle phases are states of development in the life cycle of the CN. FISEA considers in its design the proposals of ARCON and GERAM in this aspect, due the fact that these two architectures are complementary with each other. A brief description of each phase:

- Creation: This phase represents the motivation of collaboration from stakeholders into the $\mathrm{CN}$ and its incubation. In this phase are defined the teams the teams evolved, structure and roles and responsibilities.

- Conceptualization: This phase represents the strategic definition of the $\mathrm{CN}$ and its implicit negotiation.

- Definition: This phase represents the definition of $\mathrm{CN}$ business process, contract, objectives, Re-engineer tasks, KPIs, individual knowledge, sensor ontology and sensor behaviour system. 
- Operation: This phase is surely the most important; it occurs when the $\mathrm{CN}$ operates directly towards achieving its goals.

- Evolution: During the operation of a $\mathrm{CN}$ it may be necessary to make some changes to its membership, process, contract, structural relationships, and roles of its members.

- Dissolution: A CN will typically dissolve after accomplishing its goal. However, this CN could evolve into a new $\mathrm{CN}$ where the knowledge acquired generate collective learning and trust in the collaborative process.

Modelling detail level: This perspective has to do with the detail level into the modelling, being the general modelling the most neutral that could be used for any kind of $\mathrm{CN}$, partial modelling occurs when the model is developed for a specific cluster and the particular modelling is developed for a specific $\mathrm{CN}$.

Each cell in a FISEA represents the intersection of a particular life cycle phase with one modelling view, as shown in Fig. 6. Not all views include all life cycle phases because the views of process, such as knowledge and sensors behaviour, do not require the definition of elements in the beginning of the life cycle due the fact that their core is in the middle of the $\mathrm{CN}$ life cycle. Each element in FISEA represented with a bullet has an associated building block, which has the necessary information that allows modelling $\mathrm{CN}$ in sensing environments.

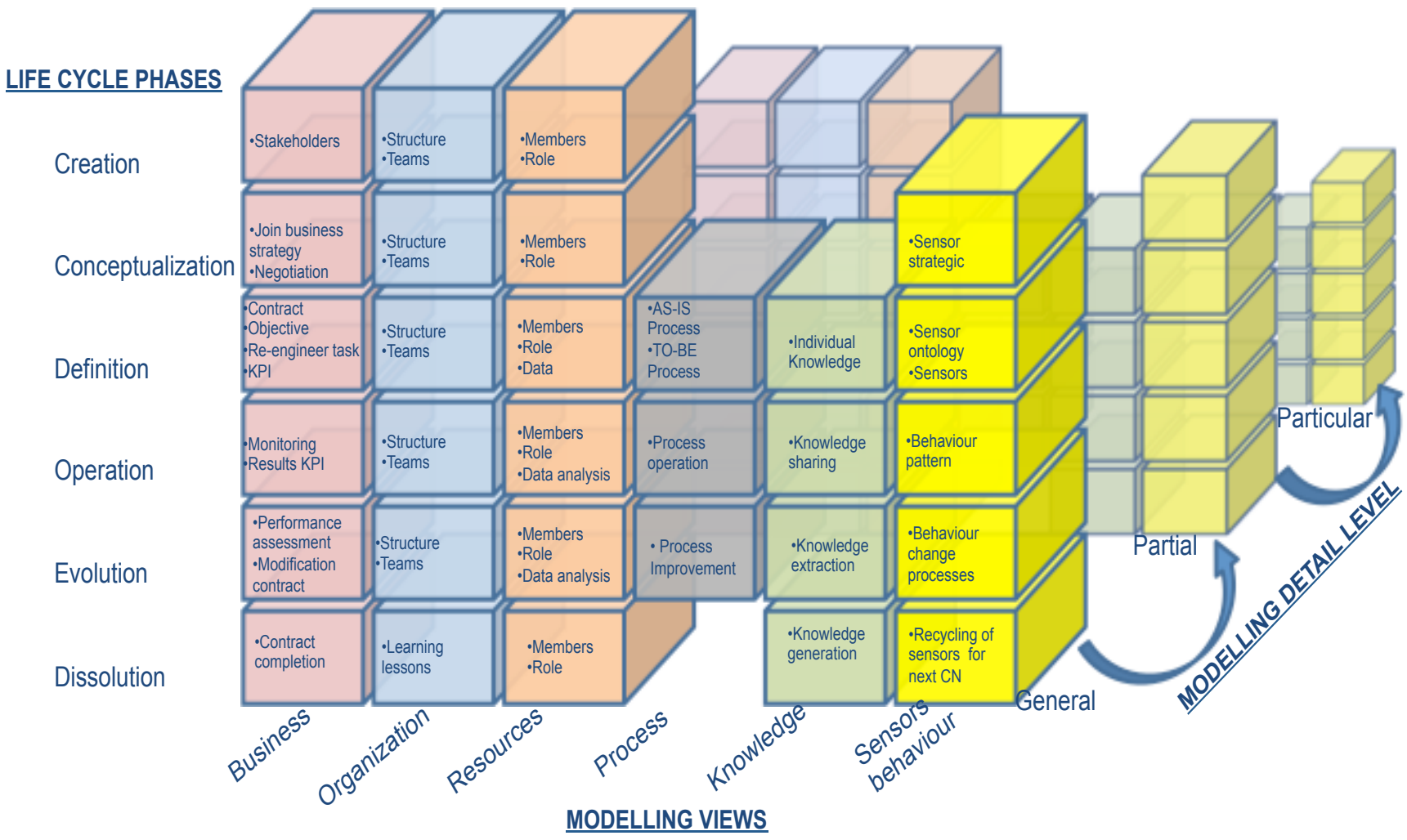

Fig. 6. Framework of Inter Sensing Enterprise Architecture (FISEA) 


\section{FISEA meta-model and validation}

\subsection{FISEA meta-model}

In order to validate the correct gear of the FISEA, Fig. 7 shows a meta-model of relationship between elements of each view in each life cycle phase, which is according to the definition of ISO 15704 (2000). This meta-model has helped to corroborate the right definition from the elements in each view and phase. Due to the complexity of the meta-model and the proposal of an easy understanding about it, some elements of organization and resources views have been omitted from the model (structure, teams, members, roles), but their participation is crucial to the life cycle phases of the CN. This metamodel is a representation of the general modelling level, for partial and particular modelling the model will change depending of the specific cluster or $\mathrm{CN}$ and their different elements. In order to model a clear and solid architecture, it is proposed to use the CIMOSA building blocks but adapting to the elements identified into the FISEA.

The meta-model shows, at a high level, how the collaborative process in a $\mathrm{CN}$ is performed through of the life cycle phases (since its creation until its dismantling) and how the different views are integrated into each life cycle phase and with each other phases. The collaboration process starts when two or more stakeholders in a SC decide to collaborate in order to create synergies that allow them to be more competitive. This phase is defined by the organizational structure of the $\mathrm{CN}$, the teams that are going to work together, and the members of each team as well as the roles of each member. Then the negotiation process starts at a higher strategic level when the management teams think and design the joint business strategy and the sensor strategy that must be aligned with each other. During the negotiation the information exchange plan has to be clear, as well as the exception handling and the compensation system. In the definition phase, the negotiation process is finished when all the stakeholders sign the contract that includes the objectives defined in the business strategy, the joint business strategy define objectives that are measured through KPIs, those objectives that have associated re-engineering tasks that seeks to evaluate the current AS-IS process to be improved in a new TO-BE process with the support of the knowledge that each organization can provide, the TO-BE processes need the data that sensors provide to keep running the process, the sensor strategy defines the sensor ontology that incorporates the definition of the sensors and the relationships between each another, as well as their implementations. Once the collaboration operation starts in the tactical and operative levels, the process is monitored taking into account the KPIs defined in previous phases, so that the contract is confirmed as being fulfilled, and in the technological level the sensors that have been installed generate a behaviour pattern that triggers the process operations that generate data and Information. This collaborative 


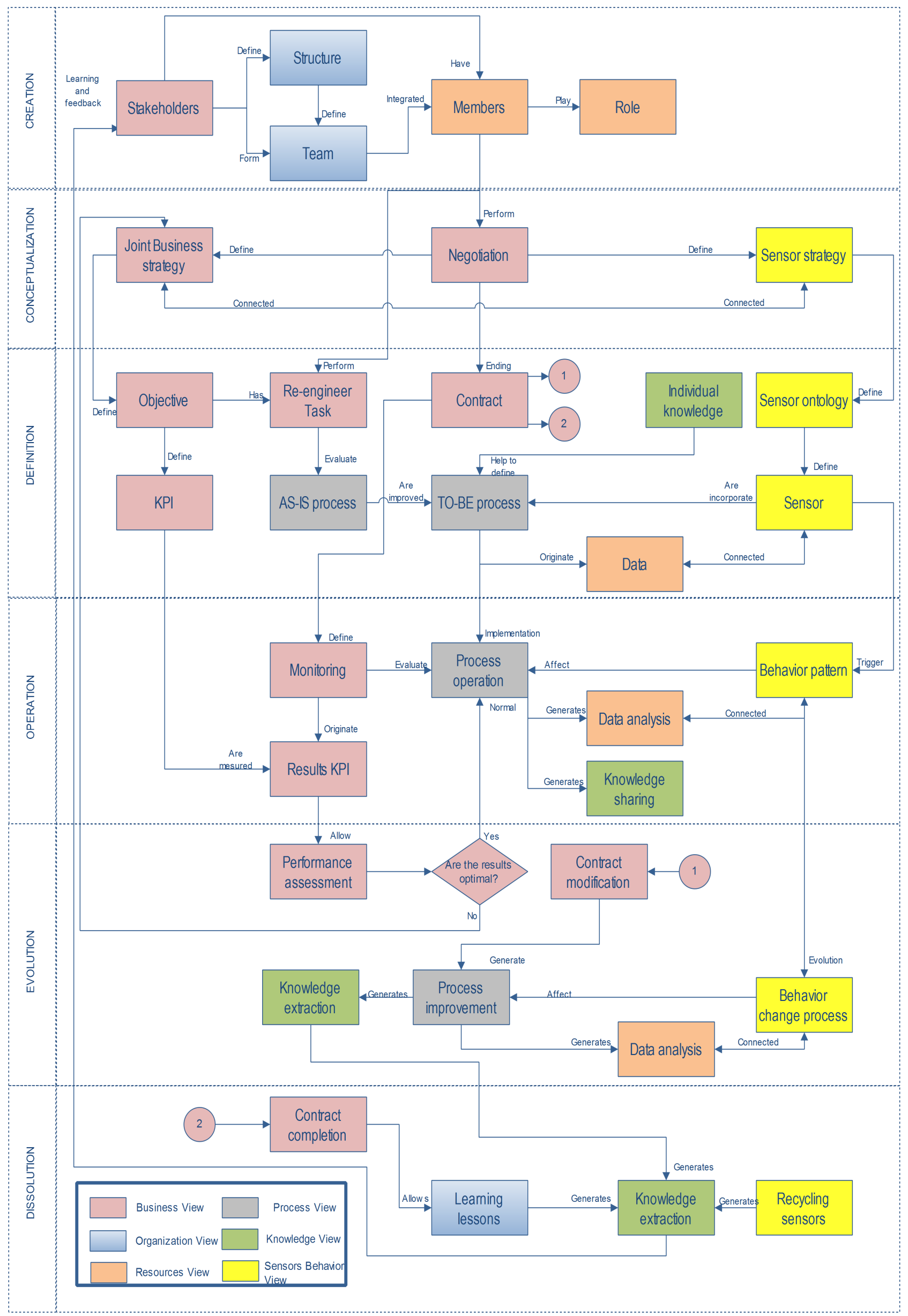

Fig.7. Relationship meta-model between elements views and phases of FISEA 
process operation generates knowledge that is shared among enterprises. In the evolution phase, the performance assessment is executed, if the results are in accordance with the objectives, the process continues in a normal way. If not, the joint business and sensor strategies have to be double-checked and the contract will be modified as well as the processes and behaviour patterns. This phase generates the knowledge extraction. The contract has to have a clause that indicates the moment or situation that triggers its completion. When this happens, the $\mathrm{CN}$ in its continuous learning process produces learning lessons that have to be stored as well as the sensors used in order to re-use them in subsequent CNs, generating continuous knowledge.

\subsection{Validation}

In order to implement the FISEA in a business environment, the instantiation of its elements has to be complete. Those elements in modelling language are called building blocks, and Table 3 describes each building block and how has it to be instantiated, as well as the modelling view and the life cycle phases that it belongs to.

Table 3. Instantiation of building blocks in FISEA

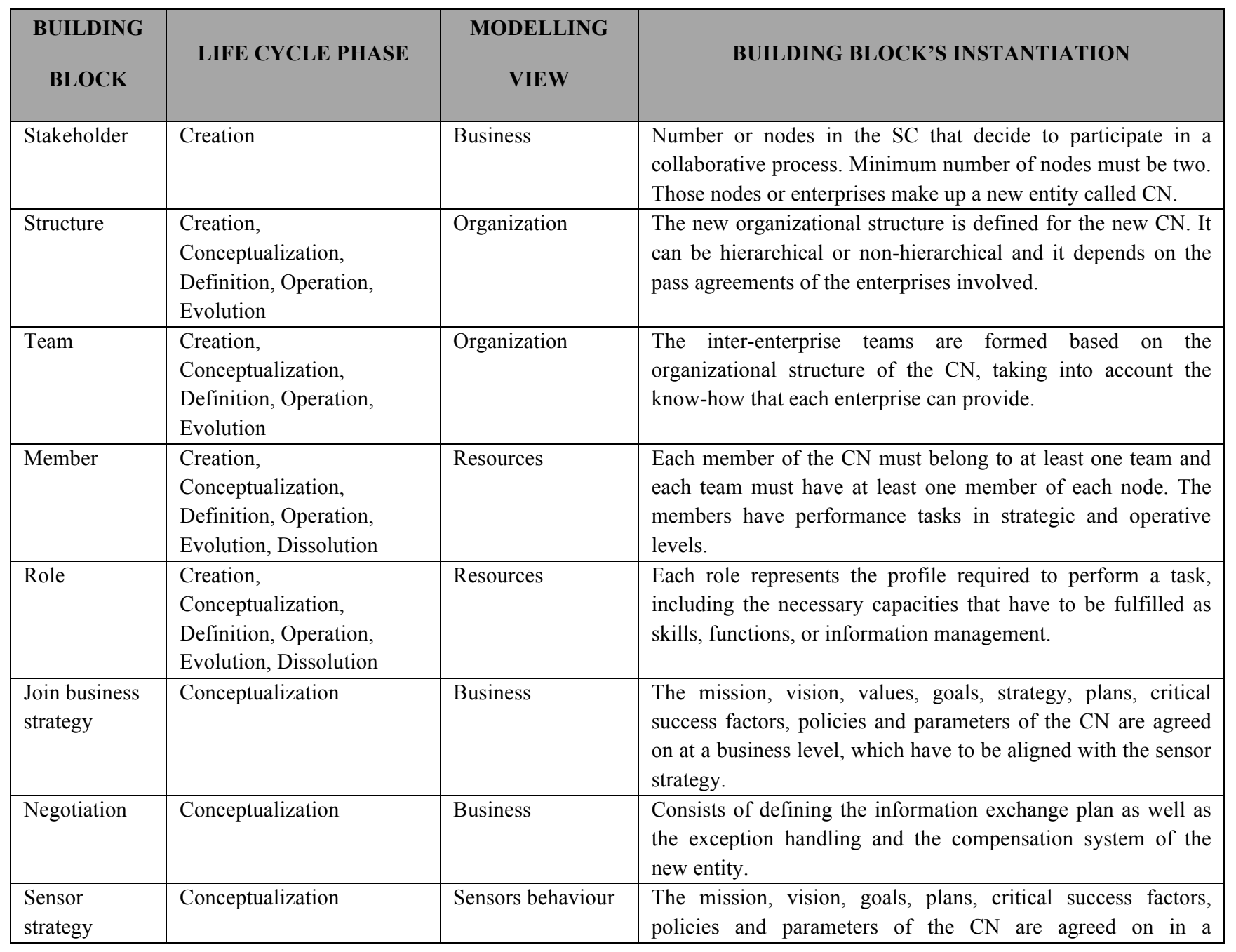




\begin{tabular}{|c|c|c|c|}
\hline & & & $\begin{array}{l}\text { technological level, which have to be aligned with the business } \\
\text { strategy. }\end{array}$ \\
\hline Objective & Definition & Business & $\begin{array}{l}\text { The objectives of the } \mathrm{CN} \text { have to be specified in quantitative } \\
\text { terms, in order to evaluate if they are being fulfilled during the } \\
\text { collaborative process. These objectives must express the goals } \\
\text { for each modelling view of the CN. }\end{array}$ \\
\hline KPI & Definition & Business & $\begin{array}{l}\text { Each objective has to have at least one KPI defined. Those } \\
\text { KPIs help CNs to define and measure progress toward } \\
\text { organizational goals. }\end{array}$ \\
\hline $\begin{array}{l}\text { Re-engineer } \\
\text { Task }\end{array}$ & Definition & Business & $\begin{array}{l}\text { In order to achieve the objectives proposed, it has to perform } \\
\text { different re-engineer task that would help to improve the AS-IS } \\
\text { process. }\end{array}$ \\
\hline Contract & Definition & Business & $\begin{array}{l}\text { The negotiation process concludes when all the parties agree } \\
\text { with the joint business strategy, sensor strategy, objectives, } \\
\text { KPIs and re-engineer tasks and sign a contract that legalize this } \\
\text { agreement. }\end{array}$ \\
\hline AS-IS process & Definition & Process & $\begin{array}{l}\text { Represents how the process is performed in the current time } \\
\text { and the identification of points to be improved in the } \\
\text { collaboration process with the use of sensor technology. }\end{array}$ \\
\hline $\begin{array}{l}\text { TO-BE } \\
\text { process }\end{array}$ & Definition & Process & $\begin{array}{l}\text { Represents how the process will be performed as soon as the } \\
\text { re-engineer tasks are done. }\end{array}$ \\
\hline $\begin{array}{l}\text { Individual } \\
\text { knowledge }\end{array}$ & Definition & Knowledge & $\begin{array}{l}\text { The know-how that each enterprise in the } \mathrm{CN} \text { can share with } \\
\text { each another makes sure that the TO-BE process is successfully } \\
\text { and integrally designs. }\end{array}$ \\
\hline Data & Definition & Resources & $\begin{array}{l}\text { The data is generated either for the sensors or for outputs that } \\
\text { produce the process itself. This data is a vital resource to run } \\
\text { the process. }\end{array}$ \\
\hline $\begin{array}{l}\text { Sensor } \\
\text { ontology }\end{array}$ & Definition & Sensors behaviour & $\begin{array}{l}\text { The sensor ontology defines the sensors, their language's } \\
\text { syntax rules and structure, as well as their relationship with } \\
\text { each another and with the process itself. }\end{array}$ \\
\hline Sensor & Definition & Sensors behaviour & $\begin{array}{l}\text { Each sensor integrated into the process generates data that is } \\
\text { necessary to keep running the process. It is necessary to define } \\
\text { which is a function of each sensor in the process. }\end{array}$ \\
\hline Monitoring & Operation & Business & $\begin{array}{l}\text { The contract signed for the } \mathrm{CN} \text { includes a clause that explain } \\
\text { how the objectives will be measured and how often and what } \\
\text { happen if the objectives are not fulfilled. }\end{array}$ \\
\hline Results KPI & Operation & Business & $\begin{array}{l}\text { The outputs of the monitoring process based on KPIs are the } \\
\text { way to measure if the processes are being performed in the } \\
\text { right way in order to achieve the goals of the } \mathrm{CN} \text {. }\end{array}$ \\
\hline $\begin{array}{l}\text { Process } \\
\text { operation }\end{array}$ & Operation & Process & $\begin{array}{l}\text { The process operation is executed when local and global design } \\
\text { definitions are implemented in order to have everything done to } \\
\text { run the TO-BE process. }\end{array}$ \\
\hline Data analysis & Operation, Evolution & Resources & $\begin{array}{l}\text { Once the process is running, the data that it generates when a } \\
\text { behaviour pattern occurs allows performance the data analysis } \\
\text { that the process needs. }\end{array}$ \\
\hline $\begin{array}{l}\text { Knowledge } \\
\text { sharing }\end{array}$ & Operation & Knowledge & $\begin{array}{l}\text { The process operation generates knowledge that is shared } \\
\text { between the different enterprises of the } \mathrm{CN} \text {. }\end{array}$ \\
\hline $\begin{array}{l}\text { Behaviour } \\
\text { pattern }\end{array}$ & Operation & Sensors behaviour & $\begin{array}{l}\text { Each sensor incorporated into the process has to define the } \\
\text { behaviour pattern, which triggers a change in the data and thus } \\
\text { the normal flow of the process. }\end{array}$ \\
\hline $\begin{array}{l}\text { Performance } \\
\text { assessment }\end{array}$ & Evolution & Business & $\begin{array}{l}\text { The results of the KPI compared with the goals defined in the } \\
\text { contract allow for definition if the results are optimal or not. If } \\
\text { the results are optimal the process continues in a normal way, } \\
\text { and if not the joint business strategy and contract have to be } \\
\text { reviewed and modified. }\end{array}$ \\
\hline $\begin{array}{l}\text { Contract } \\
\text { modification }\end{array}$ & Evolution & Process & $\begin{array}{l}\text { When the performance assessment results are unacceptable, a } \\
\text { modification in the contract is produced that will change the } \\
\text { process in order to improve it. }\end{array}$ \\
\hline $\begin{array}{l}\text { Process } \\
\text { improvement }\end{array}$ & Evolution & Business & $\begin{array}{l}\text { The process will be changed as many times as the contract } \\
\text { requires and those changes have to be documented. }\end{array}$ \\
\hline
\end{tabular}




\begin{tabular}{|l|l|l|l|}
\hline $\begin{array}{l}\text { Behaviour } \\
\text { change } \\
\text { process }\end{array}$ & Evolution & Sensors behaviour & $\begin{array}{l}\text { As the process changes, it may change the behaviour pattern } \\
\text { defined in above phases and those changes also have to be } \\
\text { documented. }\end{array}$ \\
\hline $\begin{array}{l}\text { Knowledge } \\
\text { extraction }\end{array}$ & Evolution & Knowledge & $\begin{array}{l}\text { Each time that the process is improved, it creates knowledge } \\
\text { that has to be stored. }\end{array}$ \\
\hline $\begin{array}{l}\text { Contract } \\
\text { completion }\end{array}$ & Dissolution & Business & $\begin{array}{l}\text { The contract must have a clause that tells the CN the moment } \\
\text { or situation that triggers its completion. }\end{array}$ \\
\hline $\begin{array}{l}\text { Learning } \\
\text { lessons }\end{array}$ & Dissolution & Organization & $\begin{array}{l}\text { Once the CN has fulfilled its goal, the learning lessons have to } \\
\text { be stored in order to re-use them in next CNs. }\end{array}$ \\
\hline $\begin{array}{l}\text { Knowledge } \\
\text { generation }\end{array}$ & Dissolution & Knowledge & $\begin{array}{l}\text { The learning lessons and sensor storing generate knowledge } \\
\text { that enables future CN to be even more successful. }\end{array}$ \\
\hline $\begin{array}{l}\text { Recycling } \\
\text { sensors }\end{array}$ & Dissolution & Sensors behaviour & $\begin{array}{l}\text { Once the CN has fulfilled its goal, the sensors used have to be } \\
\text { stored in order to re-use them in next CNs. }\end{array}$ \\
\hline
\end{tabular}

\section{Results and discussion}

The main advantage of using FISEA is that it meets the necessary elements of an IEA for modelling enterprises in sensing environments, including elements that VEE and DBE have contributed for building collaborative environments. Since IEA and SE are novel concepts in the current business environment, FISEA constitutes a first intent of proposing the foundations of modelling for enterprises that willing to collaborate and take advantage of the opportunities that represent sensing technology, however this framework has to be tested in different CNs in order to change or adapt its elements/building blocks in specific kind of industries.

The FISEA meta-model helps to validate the consistency and integrity of the FISEA elements. The instantiation of the elements or building blocks provides a better understanding of how the $\mathrm{CN}$ will be modelled into a real business environment. Nevertheless, the specific content of each building block will allow for modelling of this CN. Our next immediate step in the current line of research is to propose the content and form of the templates that will be used to represent each building block and its application in a $\mathrm{CN}$ in the retail sector.

\section{Conclusions}

This paper emphasizes the need for a consistent enterprise architecture framework in a context of collaboration, supported for the use of a specific kind of technology, which is framed in the goals proposed for the FInES Cluster, where sensing enterprise is a specific future line of action for the European market. This research is part of on-going studies in the field of inter-enterprise architecture. After a deep and thorough literature analysis, it was possible: conceptualizing some terms which had no singular consensus; proposing a classification for enterprise architecture (Total and Partial); suggesting the concept of Inter Enterprise Architecture and presenting a first scheme of FISEA and its meta-model, which constitute the base for next steps in current research. 
As it was mentioned at the beginning of this paper, the Inter-Enterprise Architecture should be formed for a framework, a methodology and a modelling language. In this paper, we propose an initial Framework for Inter Sensing Enterprise Architecture (FISEA). This framework allows showing the components of collaborative network architecture with the support of sensing behaviour technology, covering the life cycle phases and modelling views. The meta-model between elements, views, and phases of FISEA allows for the validation of the correct definition of the elements/building blocks for each view, their life cycle phases and their connection with each another. The instantiation of each building block helps to visualise, in a real business environment, how the modelling is implemented while avoiding the creation of abstract concepts.

In future papers, we are going to continue working in this line of research in order to propose a complete IEA supported by future internet, defining the Inter Sensing Enterprise Architecture Methodology (ISEAM) and defining the building blocks to modelling $\mathrm{CN}$ in sensing environments. Also, it is important to validate different $\mathrm{CNs}$ in order to propose specific and particular Architecture Models.

Acknowledgement: This work was supported by the European Commission FP7 UNITE Project, through its Secondment Programme.

\section{References}

Adaba, G., Rusu, L., \& Mekawy, M. (2010). Business-IT Alignment in Trade Facilitation: A Case Study. In Organizational, Business, and Technological Aspects of the Knowledge Society. Communications in Computer and Information Science, 44(112), 146-154.

Afsarmanesh, H., \& Msanjila, S. (2008). Inter-organizational trust in VBEs. In L. Camarinha-Matos, H. Afsarmanesh, \& M. Ollus (Eds.), Methods and tools for collaborative networked organizations. (pp. 91-118). New York: Springer.

Afsarmanesh, H., Camarinha-Matos, L., \& Ermilova, E. (2008). VBE Reference Framework. In L. Camarinha-Matos, H. Afsarmanesh, \& M. Ollus (Eds.), Methods and tools for collaborative networked organizations. (pp. 35-68). New York: Springer.

Arango, M., Londoño, J., \& Zapata, J. (2010). Arquitectura empresarial- Una visión general. Revista Ingenierías Universidad de Medellín, 9 (16), 101-111.

Audy, J., Lehoux, N., \& D’Amours, S. (2010). A framework for an efficient implementation of logistics collaborations. International transactions in operational research, 1-25.

Camarinha-Matos, L., \& Afsarmanesh, H. (2005). Collaborative networks: A new scientific discipline. Journal of Intelligent Manufacturing, 16 (4-5), 439-452.

Camarinha-Matos, L., \& Afsarmanesh, H. (2008). Collaborative networks: Reference Modeling. Springer.

Camarinha-Matos, L., Afsarmanesh, H., \& Ollus, M. (2008). ECOLEAD and CNO base concepts. In C.-M. L.M., H. Afsarmanesh, \& M. Ollus (Eds.), Methods and tools for collaborative networked organizations. (pp. 35-68). New York: Springer. 
Chalmeta, R., \& Grangel, R. (2003). ARDIN extension for virtual enterprise integration. The Journal of Systems and Software, 67(3), 141-152.

Chen, D., Vallespir, B., \& Doumeingts, G. (1997). GRAI integrated methodology and its mapping onto generic enterprise reference architecture and methodology. Computers in Industry, 33(2), 387-394.

Choi, Y., Kang, D., Chae, H., \& Kim, K. (2008). An enterprise architecture framework for collaboration of virtual enterprise chains. The International Journal of Advanced Manufacturing Technology, 35(11-12), 1065-1078.

CIMOSA Asociation. (1996). CIMOSA Primer on key concepts, purpose and business value.

Council of Supply Chain Management Professionals CSCMP. (2010). CSCMP. Glosary of terms. from http://cscmp.org/resources-research/glossary-terms. Accessed 9 February 2013.

Coutinho, C., Cretan, A., Ferreira, C., Ghodous, P., \& Jardim-Goncalves, R. (2014). Service-based negotiation for advanced collaboration in enterprise networks. Journal of Intelligent Manufacturing.

Cuenca, L. (2009). Marco arquitectónico para la propuesta IE-GIP. Extensión de la arquitectura CIMOSA. Aplicación a una empresa del sector cerámico. Tesis Doctoral Universidad Politecnica de Valencia .

Cuenca, L., Boza, A., \& Ortiz, A. (2011). An enterprise engineering approach for the alignment of business and information technology strategy. Int. J. Computer Integrated Manufacturing , 24 (11), 974-992.

Cuenca, L., Ortiz, A., \& Boza, A. (2005). Arquitectura de Empresa. Visión General. IX Congreso de Ingeniería de Organización, (pp. 1-8). Gijón.

Dong, X., Liu, Q., \& Yin, D. (2008). Business performance, business strategy, and information system strategic alignment: An empirical study on Chinese firms. Tsinghua Science and Technology, 13 (3), 348-354.

Ermilova, E., \& Afsarmanesh, H. (2007). Modeling and management of profiles and competencies in VBEs. Journal of intelligent manufacturing , 18(5), 561-586.

Estimali, H., Gardesh, H., \& Sikari, S. (2010). Validating ITIL maturity to strategic business-IT alignment. 2nd International Conference on Computer Technology and Development (ICCTD 2010), (pp. 556-551).

European Commission European Society and Media. (2007). Dygital Business Ecosystems. (F. Nachira, P. Dini, A. Nicolai, M. Le Louarn and L. Rivera, Eds). http://www.digital-ecosystems.org/book/. Luxembourg: Office for Official Publications of the European Communities. Accessed 15 October 2012.

Executive Branch of the U.S. Federal Government. (2012). A Common Approach to Federal Enterprise Architecture. The White House.http://www.whitehouse.gov/sites/default/files/omb/assets/egov_docs/common_approach_to_federal_ea.pdf. Accessed 13 August 2013.

Franco, R., Gomez, P., Ortiz, A., \& Navarro, R. (2012). Integrated approach for interoperability in Collaborative Networs and Service-based Ecosystems. Enterpise Interoperability V. (R. Poler, G. Doumeingts, B. Katzy, \& R. Chalmeta, Eds.) London: Springer. (pp.329-339).

Force, IFIP-IFAC Task. (1998). GERAM: Generalised Enterprise Reference Architecture and Methodology. International Federation for Information Processing. Version, 1(2), 30.

Future Internet Enterprise Systems (FInES) Cluster. (2012). FInES Research Roadmap 2025 . From http://cordis.europa.eu/fp7/ict/enet/documents/fines-research-roadmap-v30_en.pdf. Accessed 13 October 2013.

Henderson, J., \& Venkatraman, N. (1993). Strategic alignment: Leveraging information technology for transforming organizations. IBM Systems Journal , 32 (1), 472-484.

Hu, Q., \& Huang, D. (2006). Using the Balanced Scorecard to Achieve Sustained IT-Business Alignment: A Case Study. Communications of the Association for Information Systems, 17, 181-204. 
ISO 15704. (2000). Industrial automation systems - Requirements for enterprise-reference architectures and methodologies.

ISO/CEN 19439. (2006). Enterprise integration - Framework for enterprise modelling.

Kilger, C., Reuter, B., \& Stadtler, H. (2008). Collaborative Planning. In: Stadtler, H., Kilger, C. (Eds.), Supply Chain Management and Advanced Planning-Concepts, Models Software and Case Studies, 263-284. Springer Berlin Heidelberg.

Kosanke, K., Vernadat, F., \& Zelm, M. (1999). CIMOSA: enterprise engineering and integration. Computers in Industry, 40(2), 83-97.

Lankhorst, M. (2009). Enterprise Architecture at Work: Modelling, Communication and Analysis. Springer.

Luftman, J. (2004). Assessing Business-IT alignment maturity. Communications of the Association for Information Systems , 4, 99.

Maes, R. (1999). Reconsidering Information Management Through A Generic Framework. Universiteit van Amsterdam, Department of Accountancy \& Information Management.

Mehandjiev, N., \& Grefen, P. (2010). Dynamic business process formation for instant virtual enterprises. London.

Mekawy, M., Rusu, L., \& Ahmed, N. (2009). Business and IT Alignment: An Evaluation of Strategic Alignment Models. In Best Practices for the Knowledge Society. Knowledge, Learning, Development and Technology for All. 49, pp. 447455.

Moisescu, M., Sacala, I., Stanescu, A., \& Serbanescu, C. (2012). Towards Integration of Knowledge Extraction Form Process Interoperability in Future Internet Enterprise Systems. In Information Control Problems in Manufacturing. 14(1), pp. 1458-1463.

Ortiz, A. (1998). Propuesta para el Desarrollo de Programas de Integración Empresarial en Empresas Industriales. Aplicación a una Empresa del Sector Cerámico. Tesis Doctoral Universidad Politécnica de Valencia .

Palmer, C., Harding, J., Swarnkar, R., Das, B., \& Young, R. (2013). Generating rules from data mining for collaboration moderator services. Journal of intelligent manufacturing , 24, 313-330.

Pijpers, V., Gordijn, J., \& Akkermans, H. (2009). Aligning Information System Design and Business Strategy - A Starting Internet Company. In The Practice of Enterprise Modeling. Lecture Notes in Business Information Processing. $15,47-61$.

Plaza, J., Burgos, J., \& Carmona, E. (2010). Measuring Stakeholder Integration: Knowledge, Interaction and Adaptational Behavior Dimensions. Journal of Business Ethics , 93, 419-442.

Romero, D., Galeano, N. \& Molina, A. 3 (2010). Virtual organisation breeding environments value system and its elements. Journal of Intelligent Manufacturing, 21 (3), 267-286.

Sacala, I., Moisescu, M., \& Repta, D. (2013). Towards the Development of the Future Internet Based Enterprise in the Context of Cyber-Physical Systems. In 2013 19th International Conference on Control Systems and Computer Science (CSCS), (pp. 405-412).

Santana, R., Daneva, M., van Eck, P., \& Wieringa, R. (2008). Towards a business-IT aligned maturity model for collaborative networked organizations. 12 th International Conference on Advanced Information Systems Engineering, (pp. 276-287).

Schekkerman, J. (2004). Enterprise architecture validation. Achieving business-aligned and validated entreprise architectures. Institute For Enterprise Architecture Developments (IFEAD). http://enterprisearchitecture.info/Images/Extended\%20Enterprise/Extended\%20Enterprise\%20Architecture2.htm. Accessed 10 October 2011. 
Schekkerman, J. (2006). Extended Enterprise Architecture Framework Essentials Guide. Retrieved 2012 from Institute For Enterprise Architecture Developments (IFEAD). http://enterprisearchitecture.info/Images/E2AF/Extended\%20Enterprise \%20Architecture\%20Framework\%20Essentials\%20Guide\%20v1 .5.pdf. Accessed 23 September 2012.

Stadtler, H. (2009). A framework for collaborative planning and state-of-the-art. OR Spectrum , 31, 5-30.

Stelzer, D. (2010). Enterprise Architecture Principles: Literature Review and Research Directions. Service-Oriented Computing. Lecture Notes in Computer Science, 12-21.

Swarnkar, R., Choudhary, A., Harding, J., Das, B., \& Young, R. (2012). A framework for collaboration moderator services to support knowledge based collaboration. Journal of intelligent manufacturing , 23, 2003-2023.

THE OPEN GROUP. (2011). TOGAF. http://www.opengroup.org/togaf/. Accessed 18 November 2011.

U.S. Department of the Treasury . (2000). Treasury Enterprise Architecture Framework. http://www.treasury.gov/Pages/default.aspx. Accessed 23 November 2011.

United States Department of Defense. (2010). Department of Defense Architecture Framework. http://dodcio.defense.gov/dodaf20/dodaf20_capability.aspx. Accessed 28 November 2011.

Vargas, A., Boza, A., \& Cuenca, L. (2011). Towards Interoperability through Inter-enterprise Collaboration Architectures. In R. Meersman, T. Dillon, \& P. Herrero (Eds.), OTM 2011 Workshops. LNCS, 7046, $102-111$.

Vargas, A., Boza, A., Cuenca, L., \& Ortiz, A. (2013b). The importance of strategic alignment in enterprise collaboration. In J. G.-A. Prado-Prado (Ed.), Annals of Industrial Engineering. Springer.

Vargas, A., Boza, A., Cuenca, L., \& Sacala, I. (2013a). Inter-Enterprise Architecture and Internet of the Future. In Technological Innovation for the Internet of Things, 394, pp. 25-32.

Vernadat, F. (2003). Enterprise modelling and integration: From fact modelling to Enterprise Interoperability. Enterprise inter- and intra-organizational integration: Building International Consensus. Series: IFIP Advances in Information and Communication Technology, 108 .

Vesterager, J., Tølle, M., \& Bernus, P. (2002). VERA: Virtual Enterprise Reference. In GMNBook, GLOBEMEN final plenary.

Wang, X., Zhou, X., \& Jiang, L. (2008). A Method of Business and IT Alignment Based on Enterprise Architecture. IEEE International Conference on Service Operations and Logistics, and Informatics, (pp. 740-745).

Zachman, J. (1997). Enterprise Architecture: The Issue of the Century. Database Programming and Design, (pp. 1-13). 